\title{
Monitoring the impacts of drought on land use/cover: a developed object-based algorithm for NOAA AVHRR time series data
}

\begin{abstract}
This project was implemented on Zayandeh-Rud basin which is one of the most important and strategic regions of Iran. The main goal of the research was to monitor and evaluate the temporal land use/cover changes affected by drought episodes over a 10-year period (19922003). Primarily, raw weather data preparation activities were carried out to produce Standard Precipitation Index (SPI) spatial point thematic layer as a base map, then, satellite image pre-processing works applied on the remotely sensed data to generate the time series land use/cover maps. As a novel idea in this study, it developed a new object-based classification algorithm for AVHRR (Advanced Very High Resolution Radiometer) data. The model works based on the seasonal values of Normalized-difference Vegetation Index (NDVT) in the study area. The algorithm was statistically compared with maximum likelihood supervised classification method. Results demonstrated an increase in overall accuracy from 74.34 to $90.07 \%$ and the Kappa index from 70.58 to $88.8 \%$. Based on the statistical analysis results, drought had not statistically significant effect on the land use/cover changes. Therefore, there are more important factors other than natural weather drought in the study area and these could be summarized as a term of disorder on land management in the Zayandeh-Rud river basin. Results of the investigation provide a scientific tool enabling governmental land and water managers to monitor, make decision and manage the water crises due to drought upon the catchment.
\end{abstract}

Keyword: Change detection; Drought periods; Land use/cover; NOAA AVHRR; Spatial interpolation; SPI 